1 Supply and consumption of glucose 6-phosphate in the chloroplast stroma

2 Alyssa L. Preiser ${ }^{1,2}$, Aparajita Banerjee ${ }^{2}$, Nicholas Fisher ${ }^{1}$, Thomas D. Sharkey ${ }^{1,2,3}$

3 Running Title: Supply and consumption of plastidic glucose 6-phosphate

$5{ }^{1}$ MSU-DOE Plant Research Laboratory, 210 Wilson Road, Michigan State University, East

6 Lansing, MI, USA 48824; ${ }^{2}$ Department of Biochemistry and Molecular Biology, 603 Wilson

7 Road, Michigan State University, East Lansing, MI, USA 48824; Plant Resilience Institute,

8 Michigan State University, Plant Biology Laboratories, 612 Wilson Road, East Lansing, MI

$9 \quad$ USA 48824

10

11 Author for correspondence:

12 Thomas D. Sharkey

13 Tel: $+1(517) 353-4886$

14 Email: tsharkey@msu.edu

15

16 Date of submission: October 12, 2018

17 Number of Tables: 4

18 Number of Figures: 12 (Figs 6, 7, 11, and 12 in color) and 5 supplemental figures

19 Word count: 5,998 


\section{Supply and consumption of glucose 6-phosphate in the chloroplast stroma}

\section{Running Title: Supply and consumption of plastidic glucose 6-phosphate}

\section{Highlight}

23 Glucose 6-phosphate stimulates glucose-6-phosphate dehydrogenase. This enzyme is less active

24 during the day but retains significant activity that is very sensitive to the concentration of glucose

25 6-phopshate.

\section{Abstract}

27 Fructose 6-phosphate is an intermediate in the Calvin-Benson cycle and can be acted on by

28 phosphoglucoisomerase to make glucose 6-phosphate (G6P) for starch synthesis. A high

29 concentration of G6P is favorable for starch synthesis but can also stimulate G6P dehydrogenase

30 initiating the glucose-6-phosphate shunt an alternative pathway around the Calvin-Benson cycle.

31 A low concentration of glucose 6-phosphate will limit this futile cycle. In order to understand the

32 biochemical regulation of plastidic glucose 6-phosphate supply and consumption, we

33 characterized biochemical parameters of two key enzymes, phosphoglucoisomerase (PGI) and

34 G6P dehydrogenase (G6PDH). We have found that the plastidic PGI in has a higher $K_{\mathrm{m}}$ for G6P

35 compared to that for fructose 6-phosphate. The $K_{m}$ of G6PDH isoform 1 is increased under

36 reducing conditions. The other two isoforms exhibit less redox regulation; isoform 2 is the most

37 inhibited by NADPH. Our results support the conclusion that PGI restricts stromal G6P synthesis

38 limiting futile cycling via G6PDH. It also acts like a one-way valve, allowing carbon to leave the

39 Calvin-Benson cycle but not reenter. We found flexible redox regulation of G6PDH that could

40 regulate the glucose-6-phosphate shunt. 
42 Keywords: Calvin-Benson cycle, glucose-6-phosphate dehydrogenase, glucose 6-phosphate,

43 glucose 6-phosphate shunt, hydrogen peroxide, phosphoglucoisomerase, redox regulation

\section{Abbreviations:}

$45 \quad 6 \mathrm{PG}$

6-phosphogluconic acid

46 At

Arabidopsis thaliana

47 DHAP

dihydroxacetone phosphate

48 E4P

erythrose 4-phosphate

49 F6P

fructose 6-phosphate

50 FBP

fructose 1,6-bisphosphate

51 G6P

glucose 6-phosphate

52 G6PDH

glucose-6-phosphate dehydrogenase

53 PGA

3-phosphoglyceric acid

54 PGI

phosphoglucoisomerase

55 PGM

phosphoglucomutase

56 So

Spinacia oleracea

$57 \mathrm{Xu} 5 \mathrm{P}$

xylulose 5-phosphate 


\section{Introduction}

59 Glucose 6-phosphate (G6P) is the first product out of the Calvin-Benson cycle in the starch 60 synthesis pathway. However, it can also enter the oxidative pentose phosphate pathway creating 61 a G6P shunt that bypasses the nonoxidative branch of the pentose phosphate pathway reactions

62 that make up a significant part of the Calvin-Benson cycle. This pathway is generally considered 63 to occur only in the dark (Anderson et al., 1974; Buchanan, 1980; Buchanan et al., 2015; Heldt 64 and Piechulla, 2005; Scheibe et al., 1989). However, a high G6P concentration, favorable for 65 starch synthesis, could cause the shunt to occur in the light. Generally, the G6P concentration in 66 the plastid is low, much lower than its concentration in the cytosol (Gerhardt et al., 1987;

67 Sharkey and Vassey, 1989; Szecowka et al., 2013) but under some conditions the plastid G6P 68 concentration might increase depending on the production and consumption of plastid G6P.

69 Four different enzymes in the plastid can produce or consume G6P (Fig. 1). First, G6P can be 70 produced by phosphoglucoisomerase (PGI). This enzyme reversibly isomerizes fructose 6-

71 phosphate (F6P) and G6P. Analysis of mutant lines of Clarkia xantiana indicated that PGI is not

72 in great excess (Kruckeberg et al., 1989). There are two isoforms of PGI in Arabidopsis, one 73 targeted to the plastid and the other found in the cytosol. The plastid PGI in particular is likely

74 limiting given that G6P/F6P ratios in the plastid are significantly displaced from equilibrium and 75 much lower than in the cytosol (Backhausen et al., 1997; Gerhardt et al., 1987; Schnarrenberger and Oeser, 1974; Sharkey and Vassey, 1989; Szecowka et al., 2013). Plants with loss-of-function

77 mutants in the plastidic enzyme have 98.5\% less starch in leaves (Yu et al., 2000). Loss-of-

78 function mutants in the cytosolic enzyme results in increased starch and decreased sucrose (Kunz 79 et al., 2014).

80 The second enzyme affecting G6P in the chloroplast is phosphoglucomutase. This enzyme 81 converts G6P to glucose 1-phosphate. This reaction is an important step in starch synthesis.

82 Third, G6P can be transported across the chloroplast membrane by GPT2, a glucose-6-

83 phosphate/phosphate antiporter in the chloroplast membrane. GPT2 is not normally present green

84 tissue (Kammerer et al., 1998; Kunz et al., 2010) and this is corroborated by the large

85 concentration gradient in G6P between the chloroplast and cytosol (Gerhardt et al., 1987;

86 Sharkey and Vassey, 1989; Szecowka et al., 2013). However, GPT2 is important in acclimation

87 to light (Dyson et al., 2015) and is expressed in plants grown in high $\mathrm{CO}_{2}$ (Leakey et al., 2009) 
and is increased when starch synthesis is repressed by knocking out starch synthesis genes (Kunz et al. 2010). When GPT2 is present, the gradient of G6P would result in G6P import into the plastid (Gerhardt et al., 1987; Sharkey and Vassey, 1989; Szecowka et al., 2013). Finally, glucose-6-phosphate dehydrogenase (G6PDH) can oxidize G6P to 6-phosphoglucanolactone, the first step in the oxidative branch of the pentose phosphate pathway. There are six isoforms of G6PDH in Arabidopsis. Four of these are predicted to be targeted to the chloroplast where three are functional (Meyer et al., 2011; Wakao and Benning, 2005). It has been hypothesized that during the day, G6PDH initiates a G6P shunt around the Calvin-Benson cycle (Sharkey and Weise, 2016). The G6P shunt oxidizes and decarboxylates G6P to synthesize xylulose 5phosphate (Xu5P). While the G6P shunt is a futile cycle, it has been proposed to play an important role in stabilization of photosynthesis.

Our goal is to understand the kinetic regulation of the stromal G6P pool, specifically its production by PGI and its consumption by G6PDH. We will not further investigate the roles of PGM and GPT2 since PGM has been characterized because of its key role in starch synthesis

102 (Hattenbach and Heineke, 1999; Najjar, 1948; Ray and Roscelli, 1964), and GPT2 is usually not present in green photosynthetic tissue (Kammerer et al., 1998; Kunz et al., 2010). We repeated critical measurements of PGI kinetics and found that while the isomerization of F6P and G6P is reversible, PGI has a greater affinity for F6P than G6P. Novel findings describing the regulation of G6PDH indicate that G6PDH can remain fairly active during the day. We conclude that a G6P shunt is allowed and even likely in light of the kinetic parameters of G6PDH and that its activity could be modulated during the day to regulate flux through the G6P shunt.

Materials and Methods

\section{Overexpression and purification of recombinant enzymes}

111 His-tagged (N-terminal) Arabidopsis thaliana plastidic and cytosolic PGI, and C-terminal Strep112 tagged (Wakao and Benning, 2005; Wendt et al., 2000) plastidic G6PDH1, 2, and 3 genes were 113 commercially synthesized by GenScript (https://www.genscript.com). All of the plasmid

114 constructs were overexpressed in E. coli strain BL21. Cells were grown at $37^{\circ} \mathrm{C}$ to an $\mathrm{OD}_{600}$ of 1150.6 to1 and induced with $0.5 \mathrm{mM}$ isopropyl $\beta$-D-1 thiogalactopyranoside at room temperature. 116 Cells were centrifuged and resuspended in lysis buffer ( $5 \mathrm{ml}$ lysis buffer/g of pellet; $50 \mathrm{mM}$ 117 sodium phosphate, $\mathrm{pH} 8.0,300 \mathrm{mM} \mathrm{NaCl}$ ) containing $1 \mathrm{mg} \mathrm{ml}^{-1}$ lysozyme, $1 \mu \mathrm{g} \mathrm{ml}^{-1}$ of DNAseI, 
118 and 1x protease inhibitor cocktail (Sigma, www.sigmaaldrich.com). Cells were then lysed by

119 sonication (Branson Sonifier 250, us.vwr.com). The sonicator was set at 50\% duty cycle and an

120 output level of 1 . The cells were sonicated using five steps where each step consisted of $15 \mathrm{~s}$

121 pulses and $15 \mathrm{~s}$ on ice. The lysate was centrifuged and supernatant collected. For plastidic and

122 cytosolic PGI, Ni-NTA resin (Qiagen, https://www.qiagen.com) was added to the crude lysate

123 with gentle stirring for $1 \mathrm{hr}$. The mixture was loaded onto a column and washed with wash buffer

124 (50 mM sodium phosphate, $\mathrm{pH} 8.0,300 \mathrm{mM} \mathrm{NaCl}, 10 \mathrm{mM}$ imidazole) until the $\mathrm{OD}_{280}$ of the

125 effluent was less than 0.05. Protein was eluted with elution buffer (50 mM sodium phosphate $\mathrm{pH}$

$1268.0,300 \mathrm{mM} \mathrm{NaCl}, 250 \mathrm{mM}$ imidazole) containing 1x protease inhibitor cocktail. The Ni-NTA

127 column purification was performed in a cold room at $4^{\circ} \mathrm{C}$. For G6PDH1, 2, and 3, harvested

128 proteins were resuspended in cold Buffer W (IBA, www.iba-lifesciences.com) with protease

129 inhibitor cocktail, $1 \mathrm{mg} \mathrm{ml}^{-1}$ lysozyme, and $2.73 \mathrm{kU}$ DNAseI and lysed as described above.

130 Protein was purified on a Strep-Tactin column (IBA) following the manufacturer's instructions.

131 For all purified proteins, SDS-PAGE was carried out and fractions containing >95\% of total

132 protein of interest were combined and concentrated using Amicon Ultra $0.5 \mathrm{ml}$ centrifugal filters

133 (molecular weight cut off $3 \mathrm{kDa}$ ). Glycerol was added to the concentrated protein to obtain a

134 final protein solution with $15 \%$ glycerol. The glycerol stock of the proteins was aliquoted into

135 small volumes, frozen in liquid nitrogen, and stored at $-80^{\circ} \mathrm{C}$. The concentration of the proteins

136 was determined using Pierce $660 \mathrm{~nm}$ protein assay reagent kit (ThermoFisher Scientific,

137 www.thermofisher.com) using a bovine serum albumin standard. Final preparations of purified

138 protein were run on an SDS-polyacrylamide gel and stained with Coomassie Blue to check the

139 purity of the enzymes. Molecular weights were estimated from the protein construct using Vector

140 NTI (ThermoFisher Scientific, www.thermofisher.com).

141 Coupled spectrophotometric assay for PGI (F6P to G6P reaction) and G6PDH

142 The activity of the purified plastidic and cytosolic PGI and G6PDH1, 2, and 3 was studied using

143 coupled spectrophotometric assays. Concentrations of G6P and F6P were determined using

144 NADPH-linked assays measured spectrophotometrically. All assays were validated by

145 demonstrating linear product formation, proportional to the time of the assay and amount of

146 enzyme added. All coupling enzymes were added in excess so that no change in product

147 formation was seen when varying the coupling enzyme. PGI assays were done in $50 \mathrm{mM}$ bicine

148 buffer pH 7.8, containing 4.8 mM DTT, 0.6 mM NADP ${ }^{+}, 2$ U G6PDH (from Leuconostoc 
mesenteroides), varying concentrations of F6P, and $1.31 \mathrm{ng}$ plastidic or cytosolic PGI. The concentrations used to study the $K_{\mathrm{m}}$ of G6PDH for F6P were 0-4.8 mM. For G6PDH assays, the assay was done in $150 \mathrm{mM}$ Hepes buffer $\mathrm{pH} 7.2$ containing varying concentrations of NADP ${ }^{+}$, varying concentrations of G6P, and G6PDH. 8.3 ng of G6PDH1, $20 \mathrm{ng}$ of G6PDH2, and $44 \mathrm{ng}$

153 of G6PDH3 were used. The concentrations used to study the $K_{\mathrm{m}}$ of G6PDH for G6P were 0 $15444.2 \mathrm{mM}$, and the concentrations used to study $K_{\mathrm{m}}$ for $\mathrm{NADP}^{+}$were $0-11 \mu \mathrm{M}$. When G6PDH 155 was assayed varying G6P, $0.6 \mathrm{mM} \mathrm{NADP}^{+}$was added. When G6PDH was assayed varying $156 \mathrm{NADP}^{+}, 7.6 \mathrm{mM}$ G6P was added for G6PDH1 and 3 and $15.4 \mathrm{mM}$ for G6PDH2. Under these 157 conditions, less than 5\% of the non-limiting substrate was consumed over the duration of the 158 assay. The assay mixtures were prepared by adding all the components except the enzyme. 159 Activity was recorded with a dual wavelength filter photometer (Sigma ZFP2) as the change in 160 absorbance at $334-405 \mathrm{~nm}$ caused by $\mathrm{NADP}^{+}$reduction to NADPH using an extinction 161 coefficient of $6190 \mathrm{M}^{-1} \mathrm{~cm}^{-1}$. These wavelengths were used because they correspond to mercury 162 lamp emission wavelengths of the lamp used in the filter photometer. When assaying redox 163 sensitivity, G6PDH was incubated with $10 \mathrm{mM}$ DTT or hydrogen peroxide at room temperature 164 before addition to the assay. The G6P concentration was $0.3 \mathrm{mM}$. For G6P protection assays, 165 G6PDH1 was assayed at 5 mM G6P. After getting a stable baseline with G6PDH and NADP , 166 the reaction was initiated by addition of G6P and incubated at room temperature. Activity was 167 measured 30 or 60 minutes later to allow time for DTT deactivation. Less than 5\% of added G6P 168 and $\mathrm{NADP}^{+}$(non-limiting substrate) was consumed within 60 minutes.

\section{Mass spectrometry assay for PGI (G6P to F6P reaction)}

170 The activity of the purified plastidic and cytosolic PGI in the G6P to F6P direction was studied

171 using a coupled mass spectrometer assay. The assay mixture contained $50 \mathrm{mM}$ Tris $\mathrm{pH} 7.8,2.5$

$172 \mathrm{mM} \mathrm{MgCl}_{2}, 1 \mathrm{mM}$ ATP, $5 \mathrm{mM}$ DTT, $0.15 \mathrm{U}$ phosphofructokinase (from Bacillus

173 stearothermophilus), varying concentrations of G6P, and $1.6 \mathrm{ng}$ of plastidic or cytosolic PGI.

174 The assay mixtures were prepared by adding all the components except the enzyme. The reaction 175 was initiated with the enzyme. After five min, the reaction was quenched with four volumes of $176100 \%$ ice-cold methanol. Production of FBP was shown to be linear for up to ten min. Five nmol 177 of D-[UL- ${ }^{13} \mathrm{C}_{6}$ ] fructose 1,6-bisphosphate was added as an internal standard for quantification, 178 and the sample was heated for 5 minutes at $95^{\circ} \mathrm{C}$. Six volumes of $10 \mathrm{mM}$ tributylamine, $\mathrm{pH} 5.0$, 179 was added and the sample was filtered through a Mini-UniPrep 0.2 $\mu \mathrm{m}$ Syringeless Filter Device 
180 (GE Healthcare Life Sciences, Whatman). LC/MS-MS was carried out on a Waters Quattro

181 Premier system and was operated in electrospray negative ion mode with both multiple and 182 selected reaction monitoring. The capillary voltage was $2.75 \mathrm{kV}$; the cone voltage, $50 \mathrm{~V}$; the 183 extractor voltage, $5 \mathrm{~V}$. The source temperature was $120^{\circ} \mathrm{C}$ and the desolvation temperature was $184350^{\circ} \mathrm{C}$. Gas flow for the desolvation and cone was set to 800 and $501 \mathrm{hr}^{-1}$, respectively. The 185 syringe pump flow was $10 \mu 1 \mathrm{~min}^{-1}$. MassLynx software and the Acquity UPLC Console were 186 used to control the instrument. Samples were passed through an Aquity UPLC BEH Column 187 (Waters) with a multi-step gradient with eluent A (10 mM tributylamine, adjusted to pH 6 with $188500 \mathrm{mM}$ acetic acid) and eluent B (methanol): 0-1 min, 95-85\% A; 1-3 min, 85\%-65\% A; 3-3.5 $189 \min , 65-40 \%$ A; 3.5-4 min, 40-0\% A; 4-8.50 min, 0\% A; 8.5-10 min, 100\% A. The flow rate was $1900.3 \mathrm{ml} \mathrm{min}^{-1}$. FBP peaks were integrated using MassLynx software and the concentration of the 191 metabolites was quantified by comparing the peak response to a calibration curve.

\section{Kinetic characterization}

193 Enzymes were assayed at varying concentrations of substrate while keeping the concentration of 194 other substrates (if applicable) constant as described above. The $K_{\mathrm{m}}$ values for plastidic and cytosolic PGI were determined by fitting the data with non-linear regression using the Hill function in OriginPro 8.0 (OriginLab Corporation). All G6PDH isoforms showed substrate inhibition, therefore we estimated regression lines and kinetic constants by finding the minimum of the sum of the squared residuals from the following equation using Solver in Excel, where $v$ is the specific activity of the enzyme in $\mu \mathrm{mol} \mathrm{mg}^{-1} \mathrm{~min}^{-1}$ (Gray et al., 2011):

$$
v=\frac{V_{\text {max }}+V_{i}\left(s^{x} / K_{i s}^{x}\right)}{1+\frac{K_{m}^{H}}{s^{H}}+\frac{s^{x}}{K_{i s}^{x}}} \quad \text { Eq. } 2
$$

\section{Inhibition studies}

202 Different metabolites of the Calvin-Benson cycle were tested for their effect on both PGI and 203 G6PDH activity. All the metabolites were purchased from Sigma Aldrich. In metabolite 204 screening assays, metabolites were assayed at a 1:1 ratio with the substrate. To determine the $K_{i}$ 205 of G6PDH or PGI for different metabolites, the assay was carried out in presence of various 206 concentrations of F6P or G6P and other metabolites. Assay mixtures were prepared as described 207 above with different concentrations of substrate. For PGI studies, 0-0.98 mM F6P or 0-1.5 mM 
208

209

210

211

212

213

214

215

216

217

218

\section{Midpoint potential of G6PDH1}

A series of oxidation-reduction titrations was done with purified G6PDH1. Fully reduced DTT was prepared daily by combining $100 \mathrm{mM}$ DTT with $200 \mathrm{mM}$ sodium borohydride. The mixture was incubated on ice for 20 minutes and then neutralized by adding concentrated $\mathrm{HCl}$ to a final concentration of $0.2 \mathrm{M}$. The mixture was brought to a $\mathrm{pH}$ of 8 and diluted to a final concentration of $50 \mathrm{mM}$ DTT. Oxidized DTT and buffers used in the assay were also $\mathrm{pH} 8$. We used mixtures of oxidized and reduced DTT at different redox potentials, ranging from -420 to $-124 \mathrm{mV}$. The total concentration of DTT was 1-8.5 mM. $4.1 \mathrm{ng}$ of G6PDH1 was incubated in the DTT mixture and $1 \mathrm{mg} / \mathrm{ml} \mathrm{BSA}, \mathrm{pH} 8$ for $1 \mathrm{hr}$ at $25^{\circ} \mathrm{C}$ in an anaerobic environment. Activity of G6PDH was measured as described in 'Chloroplast isolation' with $0.3 \mathrm{mM}$ G6P. The data were fit to the Nernst equation for a two-electron process. We used the $E_{m}$ of DTT as determined by Hutchison and Ort (1995), -391 $\mathrm{mV}$ at $\mathrm{pH}$ 8. Oxidized and reduced DTT was quantified using modified protocols from Cho et al. (2005) and Charrier and Anastasio (2013) to calculate the potential.

$$
E_{h}=E_{m}+2.303(R T / n F) * \log _{10}\left(D T T_{o x} / D T T_{\text {red }}\right) \quad \text { Eq. } 5
$$

\section{Leaf extract assays}


234 Wild type Arabidopsis was grown in a $12 \mathrm{hr}$ photoperiod at $120 \mu \mathrm{mol} \mathrm{m}^{-2} \mathrm{~s}^{-1}$ of light. Day 235 temperature was $23^{\circ} \mathrm{C}$ and night temperature was $21^{\circ} \mathrm{C}$. Approximately $300 \mathrm{mg}$ of leaf samples 236 were collected in a $2 \mathrm{ml}$ microfuge tube and immediately frozen by plunging in liquid nitrogen. 237 Samples were ground in a Retsch mill with $4 \mathrm{~mm}$ silicone carbide particles (BioSpec Products, 238 www.biospec.com). One ml of extraction buffer (45 mM Hepes, pH 7.2, $30 \mathrm{mM} \mathrm{NaCl}, 10 \mathrm{mM}$ mannitol, 2 mM EDTA, $0.5 \%$ Triton-X-100, $1 \%$ polyvinylpolypyrrolidone, $0.5 \%$ casein, $1 \%$

240 protease inhibitor cocktail) was added to the sample and vortexed for $30 \mathrm{~s}$. The sample was

241 centrifuged for $30 \mathrm{~s}$ at maximum speed and immediately placed on ice. G6PDH activity was

242 assayed as described in "Coupled spectrophotometric assay for phosphoglucoisomerase (F6P to

243 G6P reaction) and G6PDH”. Assays that used leaf extracts were normalized by mg of

244 chlorophyll added to the assay mixture.

245 Chloroplast isolation

246 Fresh spinach was purchased at a local market for use that day. Spinach was either dark or light 247 treated for 1.5 hours before beginning isolation and petioles were kept in water to prevent 248 wilting. Arabidopsis Col-0 was grown on soil in a growth chamber at a $12 \mathrm{~h}$ light at $120 \mu \mathrm{mol} \mathrm{m}^{-}$ $2 \mathrm{~s}^{-1}, 23^{\circ} \mathrm{C}$ and $12 \mathrm{~h}$ dark at $21^{\circ} \mathrm{C}$. Plants were harvested either midday for light samples or 250 midnight for dark samples.

251 Chloroplasts were isolated using a Percoll gradient (Weise et al., 2004). Leaves were placed in a 252 chilled blender with grinding buffer (330 mM mannitol, $50 \mathrm{mM}$ Hepes, pH 7.6, $5 \mathrm{mM} \mathrm{MgCl} 2,1$ $253 \mathrm{mM} \mathrm{MnCl}_{2}, 1 \mathrm{mM}$ EDTA, $5 \mathrm{mM}$ ascorbic acid, 0.25\% BSA), blended, and then filtered through

254 four layers of cheese cloth. Filtered liquid was centrifuged and the pellet was resuspended in 255 resuspension buffer (330 mM mannitol, $50 \mathrm{mM}$ Hepes, $\mathrm{pH}$ 7.6, $5 \mathrm{mM} \mathrm{MgCl}, 1 \mathrm{mM} \mathrm{MnCl}$, $2561 \mathrm{mM}$ EDTA, $0.25 \%$ BSA). The resuspended pellet was layered on top of a $20-80 \%$ Percoll 257 gradient which was centrifuged at $1200 \mathrm{~g}$ for $7 \mathrm{~min}$. The bottom band in the gradient containing 258 the intact chloroplasts was collected. One volume of resuspension buffer was added to collected 259 chloroplasts and centrifuged at $1200 \mathrm{~g}$ for $2 \mathrm{~min}$. The pellet was resuspended in $50 \mu 1$ of water 260 and vortexed to lyse the chloroplasts. One volume of 2x buffer (100 mM Hepes, $\mathrm{pH} 7.6,10 \mathrm{mM}$ $261 \mathrm{MgCl}_{2}, 2 \mathrm{mM} \mathrm{MnCl}$, 2 mM EDTA, 2 mM EGTA, 60\% glycerol, 0.2\% Triton X-100, 0.2\% 262 PVPP) was added. Samples were stored at $-80^{\circ} \mathrm{C}$ until used for further analysis. Chlorophyll was 263 quantified by lysing $50 \mu \mathrm{l}$ of purified chloroplasts by sonication and adding supernatant to $1 \mathrm{ml}$ 
of $95 \%$ ethanol. $\mathrm{OD}_{654}$ was used to calculate the chlorophyll concentration (Wintermans and DeMots, 1965):

$$
\operatorname{mg~Chl~}=O D * 0.0398 * 0.050 \mu \mathrm{l} \quad \text { Eq. } 1
$$

267 When chloroplast isolations were used to assess activity of fully oxidized and reduced plastidic

268 G6PDH, oxidized or reduced DTT was added at a concentration of $10 \mathrm{mM}$ to each solution used 269 in the isolation. Assays that used isolated chloroplasts were normalized by mg of chlorophyll 270 added to the assay mixture.

\section{Results}

\section{Purification of recombinant PGI and G6PDH}

274 Final concentration of purified plastidic AtPGI was $15.3 \mathrm{mg} / \mathrm{ml}$ and that of cytosolic AtPGI was $27513.8 \mathrm{mg} / \mathrm{ml}$ (Supplemental Fig. S1). The molecular weight of His-tagged recombinant plastidic 276 and cytosolic AtPGI were $\sim 62.9 \mathrm{kDa}$ and $\sim 62.5 \mathrm{kDa}$ respectively. The specific activity was 787 $277 \mu \mathrm{mol} \mathrm{mg}{ }^{-1}$ protein $\mathrm{min}^{-1}$ for plastidic AtPGI and $1522 \mu \mathrm{mol} \mathrm{mg}{ }^{-1}$ protein $\mathrm{min}^{-1}$ for cytosolic

278 AtPGI. The final concentration of AtG6PDH1 was 1.66 mg/ml, AtG6PDH2 was 1.90 mg/ml, and AtG6PDH3 was $0.177 \mathrm{mg} / \mathrm{ml}$ (Supplemental Fig. S1). The molecular weight of Strep-tagged recombinant AtG6PDH1 was $\sim 65.2 \mathrm{kDa}$, AtG6PDH2 was $\sim 70.2 \mathrm{kDa}$, and AtG6PDH3 was 70.5 $\mathrm{kDa}$. The maximum specific activity was $28.0 \mu \mathrm{mol} \mathrm{mg}^{-1}$ protein $\mathrm{min}^{-1}$ for AtG6PDH1, 18.7 $\mu \mathrm{mol} \mathrm{mg} \mathrm{m}^{-1}$ protein $\mathrm{min}^{-1}$ for AtG6PDH2, and $7.1 \mu \mathrm{mol} \mathrm{mg}^{-1}$ protein $\mathrm{min}^{-1}$ for AtG6PDH3.

284 Table 1 shows the $K_{\mathrm{m}}$ (for both F6P and G6P) of plastidic and cytosolic AtPGI (Supplemental 285 Fig. S2). For plastidic AtPGI, the $K_{\mathrm{m}}$ value for G6P was $\sim 2.9$-fold higher than that for F6P. The $286 K_{\mathrm{m}}$ 's for F6P and G6P of the cytosolic enzyme were the same. DTT did not significantly 287 influence the specific activity of plastidic or cytosolic PGI (Supplemental Fig. S3).

\section{E4P and 6PG inhibition of PGI}

289 We tested different metabolites for their effect on PGI activity. Inhibition with either limiting 290 F6P or G6P was similar for both plastidic and cytosolic AtPGI. Erythrose 4-phosphate (E4P), 3291 phosphoglyceric acid (PGA), dihydroxacetone phosphate (DHAP), and 6-phosphogluconic acid 
292 (6PG) were screened (Fig. 2). Only E4P and 6PG showed significant inhibition. Inhibitory 293 effects were not different between plastidic and cytosolic AtPGI. Fig. 3 shows the activity of 294 plastidic AtPGI over a range of F6P and E4P concentrations. Activity of cytosolic AtPGI was 295 analyzed in a similar manner as shown for plastidic AtPGI (Supplemental Fig. S4). The 296 calculated $K_{\mathrm{i}}$ values of E4P and 6PG are shown in Table 1 . The $K_{\mathrm{i}}$ values for 6PG were between 297 31-203 $\mu \mathrm{M}$, depending on the isoform and substrate. E4P was shown to be more inhibitory with $298 K_{\mathrm{i}}$ 's between 1.5- $6 \mu \mathrm{M}$. Based on the Hanes-Woolf plots (Supplemental Fig. S5), E4P was 299 shown to be competitive, except above $0.04 \mathrm{mM}$, with G6P. 6PG was identified as competitive with F6P, except above $1.0 \mathrm{mM}$, and non-competitive with G6P.

\section{Regulation of PGI in isolated chloroplasts}

302 Plastidic SoPGI activity from chloroplasts from dark-treated spinach leaves had a higher $K_{\mathrm{m}}$ for 303 G6P compared to light-treated chloroplasts (Fig. 4). The $K_{m}$ of SoPGI for F6P did not change in 304 the light or dark.

\section{Kinetic characterization of G6PDH}

306 All three AtG6PDH isoforms showed substrate inhibition (Fig. 5a). The AtG6PDH $K_{\mathrm{m}}$ for G6P 307 for isoforms 1 and 3 was $0.3 \mathrm{mM}$, while the $K_{\mathrm{m}}$ for isoform 2 was approximately 34 -fold higher 308 (10.3 mM). Table 2 shows the $K_{\mathrm{m}}$ (for both G6P and $\mathrm{NADP}^{+}$), $k_{\text {cat }}$, and G6P $K_{\mathrm{i}}$ of all three 309 AtG6PDH isoforms. The catalytic efficiency of AtG6PDH1 for G6P was $190 \mathrm{mM}^{-1} \mathrm{~s}^{-1}$, of 310 AtG6PDH2 was $3.8 \mathrm{mM}^{-1} \mathrm{~s}^{-1}$, and of AtG6PDH3 was $48.7 \mathrm{mM}^{-1} \mathrm{~s}^{-1}$. For NADP ${ }^{+}$, the catalytic 311 efficiency of AtG6PDH1 was $81.4 \mathrm{mM}^{-1} \mathrm{~s}^{-1}$, of AtG6PDH2 was $30.3 \mathrm{mM}^{-1} \mathrm{~s}^{-1}$, and of 312 AtG6PDH3 was $29.2 \mathrm{mM}^{-1} \mathrm{~s}^{-1}$.

\section{Identification and characterization of inhibitors}

314 We tested ribulose 1,5-bisphosphate (RuBP), ribulose 5-phosphate (Ru5P), F6P, PGA, DHAP, 315 E4P, NADPH, and 6PG for their effect on G6PDH activity. Only NADPH showed inhibition.

316 While NADPH inhibited all three isoforms, AtG6PDH2 was the most inhibited. The calculated

$317 K_{\mathrm{i}}$ values of NADPH are shown in Table 2. NADPH was found to be competitive for all

318 isoforms based on the Hanes-Woolf plots, except above $14.5 \mu \mathrm{M}$ for G6PDH2 and above 0.15 $319 \mathrm{mM}$ for G6PDH3 (Supplemental Fig. S5). 
321 All isoforms of AtG6PDH were susceptible to deactivation by DTT, but AtG6PDH1 was the

322 most deactivated after two hours, losing approximately $90 \%$ of its activity (Fig. 6a). Kinetic

323 characterization of AtG6PDH1 incubated with $10 \mathrm{mM}$ DTT showed that decreased activity in

324 AtG6PDH1 was due to both a decrease in $k_{\text {cat }}$ and an increase in $K_{\mathrm{m}}$ and occurred over

325 approximately 45 minutes (Fig. 6b). However, the $k_{c a t}$ was less affected than the $K_{m}$ (Table 3).

326 Comparison of our results to those of Née et al. (2009), who used thioredoxins to deactivate

327 AtG6PDH1, show that DTT is an acceptable mimic of thioredoxins to deactivate AtG6PDH1.

328 Both results show that AtG6PDH1 will lose $90 \%$ of activity when fully reduced. AtG6PDH2

329 and 3 showed a decrease in $k_{\text {cat }}$, but not an increase in $K_{\mathrm{m}}$. AtG6PDH2 retained $\sim 60 \%$ of activity

330 and AtG6PDH3 retained $\sim 80 \%$ of activity. Redox deactivation of AtG6PDH can be rescued by

331 addition of hydrogen peroxide equimolar to DTT in vitro (Fig. 7a). AtG6PDH1 activity reached

332 approximately $64 \%$ activity while $79 \%$ of the DTT was still reduced (Fig. 7b). The calculated $E_{m}$

333 at this time point was $-407 \mathrm{mV}$. Based on our determined midpoint potential of AtG6PDH1 (see

334 Midpoint potential of G6PDH1), we predict AtG6PDH1 would have < 5\% activity at the redox

335 potential of the DTT. Therefore, we conclude the addition of hydrogen peroxide did not result in

336 the re-activation of G6PDH1 by oxidizing DTT but that hydrogen peroxide was directly

337 activating G6PDH1. Redox deactivation of G6PDH1 was decreased when G6P was present.

338 When G6P was present at $K_{m}$ concentration during incubation with DTT, the activity of reduced

339 AtG6PDH was higher than when G6P was not present (Fig. 8).

\section{Midpoint potential of G6PDH1}

341 We determined the activity of AtG6PDH1 in a series of oxidation-reduction potentials (Fig. 9).

342 The data was fit with the Nernst equation for a two-electron process. Incubation of AtG6PDH1 at

343 higher redox potentials (-300 to $-140 \mathrm{mV}$ ) did not increase activity any further. The midpoint

344 potential of G6PDH1 at $\mathrm{pH} 8$ was $-378 \mathrm{mV}$. This corresponds to a midpoint potential of $-318 \mathrm{mV}$ 345 at $\mathrm{pH} 7$.

\section{Activity of G6PDH in isolated chloroplasts and leaf extracts}

347 We used rapid leaf extract assays and chloroplast isolations to determine the activity of redox348 regulated SoG6PDH and AtG6PDH compared to total activity in the plastid and the whole leaf.

349 After illumination at $500 \mu \mathrm{mol} \mathrm{m}^{-2} \mathrm{~s}^{-1}$ for one hr, G6PDH activity spinach leaf extracts decreased

350 by about $35 \%$ (Fig. 10a). We also isolated chloroplasts in fully oxidizing or fully reducing 
351 conditions. Fully reduced chloroplast activity was about $50 \%$ of fully oxidized chloroplast

352 activity in both spinach and Arabidopsis (Fig. 10b).

\section{Discussion}

\section{Regulation of production of G6P}

355 High concentration of G6P in the chloroplast has been proposed to cause a G6P shunt (Fig. 12).

356 The results of this study of key enzymes regulating the stromal G6P concentration support the

357 hypothesis of the G6P shunt.

\section{$358 \quad$ PGI}

359 We propose that PGI is a key regulatory point in carbon export from the Calvin-Benson cycle. PGI acts as a one-way valve, going from F6P to G6P. The G6P/F6P ratio at equilibrium has been reported to vary from 3.70 at $10^{\circ} \mathrm{C}$ to 2.82 at $40^{\circ} \mathrm{C}$ (Dyson and Noltmann, 1968). However, in vivo measurements show the ratio of G6P/F6P in the stroma to be close to 1 (Backhausen et al., 1997; Gerhardt et al., 1987; Schnarrenberger and Oeser, 1974; Sharkey and Vassey, 1989; Szecowka et al., 2013). This disequilibrium is not seen for the cytosolic PGI where G6P/F6P ratios are 2.4-4.7 (Gerhardt et al., 1987; Sharkey and Vassey, 1989; Szecowka et al., 2013). Kinetic hydrogen isotope effects in starch, but not sucrose, also support the conclusion that plastidic PGI, but not cytosolic PGI, has insufficient activity to maintain equilibrium (Schleucher et al., 1999). The high $K_{\mathrm{m}}$ for G6P for the plastidic enzyme makes this reaction functionally irreversible, helping to explain the kinetic isotope effects only seen in starch. The difference in $K_{m}$ is seen in both recombinant plastidic Arabidopsis PGI and in isolated plastidic spinach PGI.

371 We previously assumed that PGA is a strong inhibitor of PGI (eg Sharkey and Weise 2016)

372 based on the report by Dietz (1985). Surprisingly, we did not observe this to be the case.

373 Examination of data from Dietz (1985) shows that during PGA inhibition assays, 6PG was also

374 present in the reaction mixture at $50 \mu \mathrm{M}$. The G6P/F6P disequilibrium in chloroplasts was

375 proportional to PGA (Dietz, 1985)(see his Table I) but PGA was not tested alone for its effect on 376 PGI. We found that the $K_{i}$ of plastidic PGI for 6PG with limiting F6P was $31 \mu \mathrm{M}$ or with limiting 377 G6P was $203 \mu \mathrm{M}$. Based on our findings, we propose that PGI is not inhibited by PGA, and the 378 previously seen inhibition can be explained by presence of 6PG or E4P. In vivo plastidic 
concentrations of 6PG are not known, therefore, extent of inhibition of PGI in vivo by 6PG cannot be currently determined.

PGI is inhibited by $\mu \mathrm{M}$ concentrations of E4P (Backhausen et al., 1997; Grazi et al., 1960; Salas et al., 1964). E4P may be inhibitory to both isoforms of PGI because it is a competitive inhibitor and the active sites of both isoforms may be similar (Backhausen et al., 1997). Presumably there is no $\mathrm{E} 4 \mathrm{P}$ in the cytosol since it lacks crucial enzymes in the non-oxidative branch of the pentose phosphate pathway (Schnarrenberger et al., 1995). Measurements and estimations of plastidic E4P concentrations in vivo show E4P to be $\sim 17-20 \mu \mathrm{M}$ (Backhausen et al., 1997; Bassham and Krause, 1969; Heldt et al., 1977). This is well above the $K_{\mathrm{i}}$ of E4P for plastidic PGI. Backhausen et al. (1997) propose that this regulation is necessary in order to keep photosynthetic pool sizes stable during changes in light intensity.

390 In addition to stabilizing the Calvin-Benson cycle, we propose that inhibition of PGI by E4P can 391 provide insight into the phenomenon of reverse sensitivity to $\mathrm{CO}_{2}$ and $\mathrm{O}_{2}$ of photosynthetic $\mathrm{CO}_{2}$ assimilation rate observed by Sharkey and Vassey (1989). They found that when potato leaves

393 were switched to decreased partial pressure of oxygen, rates of photosynthetic $\mathrm{CO}_{2}$ assimilation 394 decreased as a result of decreased starch synthesis. Sharkey and Vassey (1989) proposed this was 395 an effect of PGA inhibition of PGI, but because we did not find PGA to be inhibitory, we now 396 suggest that the decrease in starch synthesis is due to an increase in E4P concentrations (or 397 possibly 6PG).

398 We conclude that PGI is an important regulatory enzyme in central carbon metabolism, keeping 399 G6P concentration lower than would be present at equilibrium thereby regulating the rate of the 400 G6P shunt but also starch synthesis. Overexpression of phosphoglucomutase significantly 401 increased starch synthesis confirming that starch synthesis is regulated at PGI in addition to the 402 well-known regulation at ADPglucose pyrophosphorylase (Uematsu et al., 2012).

\section{GPT2}

404 If GPT2 is present it can import G6P from the cytosol to the chloroplast. Niewiadomski et al. 405 (2005) showed that GPT2 could restore starch accumulation to plants lacking PGI. Expression of 406 GPT2 is present in leaves when starch synthesis is blocked by loss of starch synthesis enzymes, 407 when plants are grown in high $\mathrm{CO}_{2}$, or exposed to an increase in light intensity (Dyson et al., 408 2015; Kunz et al., 2010; Leakey et al., 2009). It also is expressed in CAM plants, which require 
409

410

411

412

413

414

415

416

417

418

419

420

421

422

423

424

425

426

427

428

429

430

431

432

433

434

435

436

high rates of starch synthesis (Cushman et al., 2008; Neuhaus and Schulte, 1996). Thus, we believe that much of the time plants rely on PGI alone to supply G6P for starch synthesis and regulate PGI to regulate the supply of G6P to control the rate of the shunt. When higher rates of starch synthesis are needed GPT2 is expressed, increasing the supply of G6P (Fig. 11) but making the plant vulnerable to high rates of the G6P shunt.

\section{Regulation of consumption of G6P by G6PDH}

Stromal G6P is primarily thought of as an intermediate in starch synthesis. It is converted by phosphoglucomutase to glucose 1-phosphate. However, there are additional reactions involving stromal G6P can participate in in the plastid. Here, we investigated consumption of G6P by G6PDH. G6PDH is competitively inhibited by its product NADPH and redox regulation that results mostly in an increase in $K_{\mathrm{m}}$, which reduces futile cycling in leaves in the light (Scheibe $e t$ al., 1989; Wakao and Benning, 2005). However, while the enzyme is less active in the light (Anderson et al., 1974; Buchanan, 1980; Buchanan et al., 2015; Heldt and Piechulla, 2005; Scheibe et al., 1989) our results show that it retains significant activity. Two factors that will modulate G6PDH activity in the light are the sensitivity of G6PDH to G6P and the redox regulation of G6P.

\section{Sensitivity to G6P}

The activity of G6PDH (and thus the G6P shunt) is sensitive to stromal G6P concentration by three mechanisms.

- Deactivation of G6PDH in reducing conditions is primarily due to an increase in $K_{m}$ (Scheibe et al., 1989, Fig 6).

- G6P protects G6PDH from deactivation in reducing conditions (Fig 8).

- G6P has been shown to relieve the inhibition of G6PDH by NADPH, as well as decrease the $K_{m}$ and increases the $k_{c a t}$ of G6PDH in assays where NADP is varied (Olavarría et al., 2012; Shreve and Levy, 1980).

In conditions where G6P concentrations in the stroma may increase, such as those discussed above in "Production of G6P", flux through G6PDH (and the G6P shunt) would also increase.

\section{Redox Regulation}


437 We have determined the midpoint potential of G6PDH to be $-378 \mathrm{mV}$ at $\mathrm{pH}$ 8. This agrees with

438 results from Née et al. (2009) and is close to the midpoint potential of other redox regulated

439 enzymes in the Calvin-Benson cycle and electron transport (Cammack et al., 1977; Hirasawa et

440 al., 1998; Hirasawa et al., 2000; Hirasawa et al., 1999; Knaff, 2000; Née et al., 2009; Strand et

441 al., 2016). Assuming equilibrium and the midpoint potential of G6PDH1 at pH 8 as a reference,

442 using the Nernst equation, we calculate that all Calvin-Benson enzymes and electron transport

443 proteins are almost fully reduced and thus active while G6PDH maintains 50\% of its activity

444 (Table 4). Exceptions are ferredoxin and malate dehydrogenase (MDH), which are predicted to

445 be oxidized at $-378 \mathrm{mV}$. Although there may be deviations from redox equilibrium within the

446 stroma, from these approximations we conclude that the midpoint potential of AtG6PDH1 is in a

447 range to allow dynamic regulation of G6PDH and that it is theoretically possible to have flux

448 through the Calvin-Benson cycle and the G6P shunt at the same time.

449 We have also shown that G6PDH can be activated upon addition of hydrogen peroxide. Brennan

450 and Anderson (1980) and Née et al. (2009) previously demonstrated a role for hydrogen

451 peroxide regulation of G6PDH both in vivo and in vitro in the presence of thioredoxin. In

452 conditions where hydrogen peroxide can accumulate, such as high light, G6PDH deactivation

453 could be reversed to modulate the consumption of G6P by the G6P shunt. The activity of

454 G6PDH can be modulated by redox status of the plastid, G6P concentration, and hydrogen

455 peroxide.

456 Redox regulation of dominant isoforms of G6PDH is found in many species, including

457 Arabidopsis, pea, potato, spinach, and barley (Scheibe et al., 1989; Schnarrenberger et al., 1973;

458 Semenikhina et al., 1999; Wenderoth et al., 1997; Wendt et al., 2000; Wright et al., 1997). We

459 have shown that plastidic G6PDH from isolated Arabidopsis chloroplasts retains approximately

$46050 \%$ of its total activity, even in high light conditions. Additionally, cytosolic G6PDH is not

461 redox regulated and makes up 33\% of whole leaf G6PDH activity. G6P in the cytosol could be

462 converted to pentose phosphate and be imported into the plastid by the XPT transporter (Eicks et

$463 a l ., 2002)$.

464 Oxidative stress might also stimulate the G6P shunt. Drought or high light can result in an 465 accumulation of hydrogen peroxide and other ROS products (see Suzuki et al. (2011) for a

466 review). Based on current findings, we propose that, with accumulation of hydrogen peroxide, 
467 the $K_{\mathrm{m}}$ of G6PDH1 can decrease, increasing the flux through the G6P shunt. Sharkey \& Weise

468 (2016), proposed that the shunt can induce cyclic electron flow, which may help protect PSI.

469 Photoprotective mechanisms of PSII, for example state transitions of the antenna complex or

470 energy dependent quenching, are usually sufficient to safely dissipate excess excitation energy at

471 PSII (Derks et al., 2015). However, with high light, in fluctuating light (Allahverdiyeva et al.,

472 2014), and at low temperature (Sonoike, 2011), excess energy or electrons could still be passed

473 on to PSI and result in PSI photoinhibition. Unlike PSII, the proteins of PSI have a low turnover

474 rate and damage to PSI is considered more severe (Scheller and Haldrup, 2005; Sonoike, 2011).

475 Coupling ATP consumption in the G6P shunt with cyclic electron flow would dissipate light

476 energy at PSI (Miyake et al., 2004; Munekage et al., 2004; Strand and Kramer, 2014).

\section{Conclusion}

478 Our data supports the conclusion that production and consumption of plastidic G6P is carefully

479 regulated. Plastidic PGI activity is not adequate to bring F6P and G6P to equilibrium, preventing

480 an accumulation of G6P, and G6PDH is partially deactivated reducing loss of carbon while still

481 maintaining regulatory flexibility to increase and decrease the G6P shunt (Fig. 12) as needed.

\section{Supplementary data}

483 Supplemental Fig. S1- SDS page of the purified G6PDH and PGI proteins, stained with

484 Coomassie blue.

485 Supplemental Fig. S2- Kinetics of plastidic and cytosolic AtPGI at different F6P and G6P 486 concentrations.

487 Supplemental Fig. S3- Effect of $10 \mathrm{mM}$ DTT on plastidic and cytosolic AtPGI

488 Supplemental Fig. S4- Hanes-Woolf plots of E4P and 6PG inhibition of plastidic AtPGI

489 Supplemental Fig. S5- Hanes-Woolf plots of NADPH effect on G6PDH1

\section{Acknowledgements}

491 We thank Michigan State University Research Technology Support Facility Mass Spectrometry

492 Core for providing the facility for doing the LC-MS/MS work. This research was funded by U.S.

493 Department of Energy Grant DE-FG02-91ER2002 (T.D.S. and A.L.P) and DE-FG02-

494 11ER16220 (N.F.). A.L.P is partially supported by a fellowship from Michigan State University

495 under the Training Program in Plant Biotechnology for Health and Sustainability (T32-

496 GM110523). Partial salary support for T.D.S. came from Michigan AgBioResearch. 


\section{Author Contributions}

498 A.L.P. designed and carried out the experiments and analyzed the data. A.B. designed and

499 carried out the PGI experiments. N.F. did the calculations for the midpoint potential experiments.

500 A.L.P. wrote the manuscript. T.D.S. supervised the project and edited the manuscript. All

501 authors discussed the results and provided critical feedback. 


\section{References}

Allahverdiyeva Y, Suorsa M, Tikkanen M, Aro E-M. 2014. Photoprotection of photosystems in fluctuating light intensities. Journal of Experimental Botany 66, 2427-2436.

Anderson LE, Ng T-CL, Kyung-Eun Yoon P. 1974. Inactivation of pea leaf chloroplastic and cytoplasmic glucose 6-phosphate dehydrogenases by light and dithiothreitol. Plant Physiology 53, 835-839.

Au SW, Grover S, Lam VM, Adams MJ. 2000. Human glucose-6-phosphate dehydrogenase: the crystal structure reveals a structural NADP+ molecule and provides insights into enzyme deficiency. Structure 8, 293-303.

Backhausen JE, Jöstingmeyer P, Scheibe R. 1997. Competitive inhibition of spinach leaf phosphoglucose isomerase isoenzymes by erythrose 4-phosphate. Plant Science 130, 121-131.

Bassham JA, Krause GH. 1969. Free energy changes and metabolic regulation in steady-state photosynthetic carbon reduction. Biochimica et Biophysica Acta 189, 207-221.

Brennan T, Anderson LE. 1980. Inhibition by catalase of dark-mediated glucose-6-phosphate dehydrogenase activation in pea chloroplasts. Plant Physiology 66, 815-817.

Buchanan BB. 1980. Role of light in the regulation of chloroplast enzymes. Annual Review of Plant Physiology 31, 341-374.

Buchanan BB, Gruissem W, Jones RL. 2015. Biochemistry \& Molecular Biology of Plants. Rockville: American Society of Plant Physiologists.

Cammack R, Rao KK, Bargeron CP, Hutson KG, Andrew PW, Rogers LJ. 1977. Midpoint redox potentials of plant and algal ferredoxins. Biochemical Journal 168, 205-209.

Cappellini MD, Fiorelli G. 2008. Glucose-6-phosphate dehydrognease deficiency. Lancet 371, 64-74.

Charrier JG, Anastasio C. 2013. On dithiothreitol (DTT) as a measure of oxidative potential for ambient particles: evidence for the importance of soluble transition metals. Atmospheric Chemistry and Physics 12, 11317-11350.

Cho AK, Sioutas C, Miguel AH, Kumagai Y, Schmitz DA, Singh M, Eiguren-Fernandez A, Froines JR. 2005. Redox activity of airborne particlate matter at different sites in the Los Angeles Basin. Environmental Research 99, 40-47. 
Cushman JC, Tillett RL, Wood JA, Branco JM, Schlauch KA. 2008. Large-scale mRNA expression profiling in the common ice plant, Mesembryanthemum crystallinum, performing $\mathrm{C}_{3}$ photosynthesis and Crassulacean acid metabolism (CAM). Journal of Experimental Botany 59, 1875-1894.

Derks A, Schaven K, Bruce D. 2015. Diverse mechanisms for photoprotection in photosynthesis. Dynamic regulation of photosystem II excitation in response to rapid environmental change. Biochimica et Biophysica Acta Bioenergetics 1847, 468-485.

Dietz KJ. 1985. A possible rate limiting function of chloroplast hexosemonophosphate isomerase in starch synthesis of leaves. Biochimica et Biophysica Acta 839, 240-248. Dyson BC, Allwood JW, Feil R, Xu YUN, Miller M, Bowsher CG, Goodacre R, Lunn JE, Johnson GN. 2015. Acclimation of metabolism to light in Arabidopsis thaliana: the glucose 6phosphate/phosphate translocator GPT2 directs metabolic acclimation. Plant, Cell \& Environment 38, 1404-1417.

Dyson JED, Noltmann EA. 1968. The effect of $\mathrm{pH}$ and temperature on the kinetic parameters of phosphoglucose isomerase. The Journal of Biological Chemistry 243, 1401-1414.

Eicks M, Maurino V, Knappe S, Flügge U-I, Fischer K. 2002. The plastidic pentose phosphate translocator represents a link between the cytosolic and the plastidic pentose phosphate pathways in plants. Plant Physiology 128, 512-522.

Gerhardt R, Stitt M, Heldt HW. 1987. Subcellular metabolite levels in spinach leaves.

Regulation of sucrose synthesis during diurnal alterations in photosynthetic partitioning. Plant Physiology 83, 399-407.

Gray DW, Breneman SR, Topper LA, Sharkey TD. 2011. Biochemical characterization and homology modeling of methyl butenol synthase and implications for understanding hemiterpene synthase evolution in plants. Journal of Biological Chemistry 286, 20582-20590.

Grazi E, De Flora A, Pontremoli S. 1960. The inhibition of phosphoglucose isomerase by Derythrose 4-phosphate. Biochem Biophys Res Commun 2, 121-125.

Hattenbach A, Heineke D. 1999. On the role of choroplastic phosphoglucomutase in the regulation of starch turnover. Planta 207, 527-532.

Heldt H-W, Piechulla B. 2005. Plant Biochemistry. Burlington MA: Elsevier Academic Press. 
Heldt HW, Chon CJ, Maronde D, Herold A, Stankovic ZS, Walker DA, Kraminer A, Kirk MR, Heber U. 1977. Role of orthophosphate and other factors in the regulation of starch formation in leaves and isolated chloroplasts. Plant Physiology 59, 1146-1155.

Hirasawa M, Brandes HK, Hartman FC, Knaff DB. 1998. Oxidation-reduction properties of the regulatory site of spinach phosphoribulokinase. Archives of Biochemistry and Biophysics 350, 127-131.

\section{Hirasawa M, Ruelland E, Schepens I, Issakidis-Bourguet E, Miginiac-Maslow M, Knaff}

DB. 2000. Oxidation-reduction properties of the regulatory disulfieds of sorghum chloroplast nicotinamide adenine dinucleotide phosphate-malate dehydrogenase. Biochemistry 39, 33443350.

\section{Hirasawa M, Schürmann P, Jacquot JP, Manieri W, Jacquot P, Keryer E, Hartman FC,} Knaff DB. 1999. Oxidation-reduction properties of chlorplast thioredoxins, ferredoxin:thioredoxin reductase, and thioredoxin f-regulated enzymes. Biochemistry 38, 52005205.

Hutchison RS, Ort DR. 1995. Measurment of equilibrium midpoint potentials of thiol/disulfide regulatory groups on thioredoxin activated chloroplast enzymes. Methods in Enzymology 252, 220-228.

Kammerer B, Fischer K, Hilpert B, Schubert S, Gutensohn M, Weber A, Flügge UI. 1998.

Molecular characterization of a carbon transporter in plastids from heterotrophic tissues: The glucose 6-phosphate phosphate antiporter. The Plant Cell 10, 105-117.

Knaff DB. 2000. Oxidation-reduction properties of thioredoxins and thioredoxin-regulated enzymes. Physiologia Plantarum 110, 309-313.

Kruckeberg AL, Neuhaus HE, Feil R, Gottlieb LD, Stitt M. 1989. Decreased-activity mutants of phosphoglucose isomerase in the cytosol and chloroplast of Clarkia xantiana . Impact on mass-action ratios and fluxes to sucrose and starch, and estimation of flux control coefficients and elasticity coefficients. Biochemical Journal 261, 457-467.

Kunz HH, Häusler RE, Fettke J, Herbst K, Niewiadomski P, Gierth M, Bell K, Steup M, Flügge UI, Schneider A. 2010. The role of plastidial glucose-6-phosphate/phosphate translocators in vegetative tissues of Arabidopsis thaliana mutants impaired in starch biosynthesis. Plant Biology 12, 115-128. 
Kunz HH, Zamani-Nour S, Hausler RE, Ludewig K, Schroeder JI, Malinova I, Fettke J, Flugge UI, Gierth M. 2014. Loss of cytosolic phosphoglucose isomerase affects carbohydrate metabolism in leaves and is essential for fertility of Arabidopsis. Plant Physiol 166, 753-765.

Leakey ADB, Xu F, Gillespie KM, McGrath JM, Ainsworth EA, Ort DR. 2009. Genomic basis for stimulated respiration by plants growing under elevated carbon dioxide. Proceedings of the National Academy of Sciences 106, 3597-3602.

Meyer T, Hölscher C, Schwöppe C, Von Schaewen A. 2011. Alternative tageting of Arabidopsis plastidic glucose-6-phosphate dehydrogenase G6PD1 involves cysteine-dependent interaction with G6PD4 in the cytosol. The Plant Journal 66, 745-758.

Miyake C, Shinzaki Y, Miyata M, Tomizawa K. 2004. Enhancement of cyclic electron flow around PSI at high light and its contribution to the induction of non-photochemical quenching of chl fluorescence in intact leaves of tobacco plants. Plant and Cell Physiology 45, 1426-1433. Munekage Y, Hashimoto M, Miyaka C, Tomizawa KI, Endo T, Tasaka M, Shikanai T. 2004. Cyclic electron flow around photosystem I is essential for photosynthesis. Nature 429, $579-582$.

Najjar VA. 1948. The isolation and properties of phosphoglucomutase. Journal of Biological Chemistry 175, 281-290.

Née G, Zaffagnini M, Trost P, Issakidis-Bourguet E. 2009. Redox regulation of chloroplastic glucose-6-phosphate dehydrogenase: A new role for f-type thioredoxin. FEBS Letters 583, 2827 2832.

Neuhaus HE, Schulte N. 1996. Starch degradation in chloroplasts isolated from $\mathrm{C}_{3}$ or CAM (crassulacean acid metabolism)-induced Mesembryanthemum crystallinum L. Biochemical Journal 318, 945-953.

Niewiadomski P, Knappe S, Geimer S, Fischer K, Schulz B, Unte US, Rosso MG, Ache P, Flugge UI, Schneider A. 2005. The Arabidopsis plastidic glucose 6-phosphate/phosphate translocator GPT1 is essential for pollen maturation and embryo sac development. The Plant Cell 17, 760-775.

Olavarría K, Valdés D, Cabrera R. 2012. The cofactor preference of glucose-6-phosphate dehydrogenase from Escherichia coli - modelling the physiological production of reduced cofactors. FEBS J 279, 2296-2309. 
Ray WJ, Roscelli GA. 1964. A kinetic study of the phosphoglucomutase pathway. Journal of Biological Chemistry 239, 1228-1236.

Salas M, Viñuela E, Sols A. 1964. Spontaneous and enzymatically catalyzed anomerization of glucose 6-phosphate and anomeric specificity of related enzymes. The Journal of Biological Chemistry 240, 561-568.

Scheibe R, Geissler A, Fickenscher K. 1989. Chloroplast glucose-6-phosphate dehydrogenase: $K_{m}$ shift upon light modulation and reduction. Archives of Biochemistry and Biophysics 274, 290-297.

Scheller HV, Haldrup A. 2005. Photoinhibition of photosystem I. Planta 221, 5-8.

Schleucher J, Vanderveer P, Markley JL, Sharkey TD. 1999. Intramolecular deuterium distributions reveal disequilibrium of chloroplast phosphoglucose isomerase. Plant, Cell \& Environment 22, 525-533.

Schnarrenberger C, Flechner A, Martin W. 1995. Enzymatic evidence for a complete oxidative pentose phosphate pathway in chloroplasts and an incomplete pathway in the cytosol of spinach leaves. Plant Physiology 108, 609-614.

Schnarrenberger C, Oeser A. 1974. Two isoenzymes of glucosephosphate isomerase from spinach leaves and their intracellular compartmentation. European Journal of Biochemistry $\mathbf{4 5}$, 77-82.

Schnarrenberger C, Oeser A, Tolbert NE. 1973. Two enzymes each of glucose-6-phosphate dehydrogenase and 6-phosphogluconate dehydrogenase in spinach leaves. Archives of Biochemistry and Biophysics 154, 438-448.

Semenikhina AV, Popova A, Matasova LV. 1999. Catalytic properties of glucose-6-phosphate dehydrogenase from pea leaves. Biochemistry 64, 863-866.

Sharkey TD, Vassey TL. 1989. Low oxygen inhibition of photosynthesis is caused by inhibition of starch synthesis. Plant Physiology 90, 385-387.

Sharkey TD, Weise SE. 2016. The glucose 6-phosphate shunt around the Calvin-Benson Cycle. Journal of Experimental Botany 67, 4067-4077.

Shreve DS, Levy HR. 1980. Kinetic mechanism of glucose-6-phosphate dehydrogenase from the lactating rat mammary gland. Journal of Biological Chemistry 255, 2670-2677.

Sonoike K. 2011. Photoinhibition of photosystem I. Physiologia Plantarum 142, 56-64. 
Strand DD, Fisher N, Davis GA, Kramer D. 2016. Redox regulation of the antimycin A sensitive pathway of cyclic electron flow around photosystem I in higher plant thylakoids. Biochimica et Biophysica Acta Bioenergetics 1857, 1-6.

Strand DD, Kramer D. 2014. Control of non-photochemical exciton quenching by the proton circuit of photosynthesis. In: Demmig-Adams B, Garab G, Adams Iii WW, Gonvindjee, eds. Non-photochemical quenching and energy dissipation in plants, algae and cyanobacteria, Vol. 40: Springer, 387-408.

Suzuki N, Koussevitzky S, Mittler R, Miller G. 2011. ROS and redox signalling in the response of plants to abiotic stress. Plant Cell and Environment 35, 259-270.

\section{Szecowka M, Heise R, Tohge T, Nunes-Nesi A, Vosloh D, Huege J, Feil R, Lunn J,}

Nikoloski Z, Stitt M, Fernie AR, Arrivault S. 2013. Metabolic fluxes in an illuminated Arabidopsis rosette. The Plant Cell Online 25, 694-714.

Uematsu K, Suzuki N, Iwamae T, Inui M, Yukawa H. 2012. Expression of Arabidopsis plastidial phosphoglucomutase in tobacco stiumulates photosynthetic carbon flow into starch synthesis. Journal of Plant Physiology 169, 1454-1462.

Wakao S, Benning C. 2005. Genome-wide analysis of glucose-6-phosphate dehydrogenases in Arabidopsis. The Plant Journal 41, 243-256.

Weise SE, Weber A, Sharkey TD. 2004. Maltose is the major form of carbon exported from the chloroplast at night. Planta 218, 474-482.

Wenderoth I, Scheibe R, von Schaewen A. 1997. Identification of the cysteine residues involved in redox modification of plant plastidic glucose-6-phosphate dehydrogenase. Journal of Biological Chemistry 272, 26985-26990.

Wendt UK, Wenderoth I, Tegeler A, von Schaewen A. 2000. Molecular characterization of a novel glucose-6-phosphate dehydrogenase from potato (Solanum tuberosum L.). The Plant Journal 23, 723-733.

Wintermans JGFM, DeMots A. 1965. Spectrophotometric characteristics of chlorophylls a and $\mathrm{b}$ and their pheophytins in ethanol. Biochimica et Biophysica Acta 109, 448-453.

Wright DP, Huppe HC, Turpin DH. 1997. In vivo and in vitro studies of glucose-6-phosphate dehydrogenase from barley root plastids in relaiton to reductant supply for $\mathrm{NO}_{2}{ }^{-}$assimilation. Plant Physiology 114, 1413-1419. 
bioRxiv preprint doi: https://doi.org/10.1101/442434; this version posted October 21,2018 . The copyright holder for this preprint (which was not certified by peer review) is the author/funder. All rights reserved. No reuse allowed without permission.

Yu TS, Lue WL, Wang SM, Chen J. 2000. Mutation of Arabidopsis plastid phosphoglucose isomerase affects leaf starch synthesis and floral initiation. Plant Physiology 123, 319-326. 


\begin{tabular}{ccccc} 
& \multicolumn{2}{c}{ F6P $\rightarrow$ G6P } & \multicolumn{2}{c}{ G6P $\rightarrow$ F6P } \\
\cline { 2 - 5 } & Plastidic PGI & Cytosolic PGI & Plastidic PGI & Cytosolic PGI \\
\hline$K_{m}(\mu \mathrm{M})$ & $73 \pm 46$ & $203 \pm 7$ & $164 \pm 25$ & $158 \pm 49$ \\
$\mathrm{E} 4 \mathrm{P} K_{i}(\mu \mathrm{M})$ & 2.3 & 1.5 & 6.0 & 3.7 \\
$6 \mathrm{PG} K_{i}(\mu \mathrm{M})$ & 31 & 106 & 245 & 44 \\
\hline
\end{tabular}

Table 1. Kinetic constants and inhibition constants for plastidic and cytosolic AtPGI as determined by NADPH-linked spectrophotometric assays and LC-MS/MS assays. Each number was determined from the fitted curve as described in the methods. 


\section{G6PDH1}

G6PDH2

G6PDH3

\begin{tabular}{cccc}
\hline G6P $K_{m}(\mathrm{mM})$ & 0.3 & 10.3 & 0.3 \\
G6P $K_{i}(\mathrm{mM})$ & 18.9 & 30.0 & 37.0 \\
NADP $K_{m}(\mu \mathrm{M})$ & 0.7 & 1.3 & 0.6 \\
$k_{\text {cat }}\left(\mathrm{s}^{-1}\right)$ & 57.0 & 39.4 & 14.6 \\
Catalytic Efficiency & 190.0 & 3.8 & 48.7 \\
G6P $\left(\mathrm{mM}^{-1} \mathrm{~s}^{-1}\right)$ & & & \\
Catalytic Efficiency & 81.4 & 30.3 & 29.2 \\
NADP $\left(\mu \mathrm{M}^{-1} \mathrm{~s}^{-1}\right)$ & 59 & 0.9 & 112 \\
NADPH $K_{i}(\mu \mathrm{M})$ & & & \\
\hline
\end{tabular}

Table 2. Kinetic constants and inhibition constants of AtG6PDH1, 2, and 3 as determined by NADPH-linked spectrophotometric assays. Each number was determined from by a modified Michalis-Menten equation which includes substrate inhibition. Data points used in model fitting were $n=3$ different preparations. For inhibition constants, each number was determined from the fitted curves as described in the methods. 


\begin{tabular}{ccccc}
\hline & & G6PDH1 & G6PDH2 & G6PDH3 \\
\cline { 2 - 5 } Oxidized & G6P $K_{m}(\mathrm{mM})$ & 0.3 & 10.3 & 0.3 \\
& $k_{\text {cat }}\left(\mathrm{s}^{-1}\right)$ & 57.0 & 39.4 & 14.6 \\
Reduced & G6P $K_{m}(\mathrm{mM})$ & 3.4 & 8.6 & 0.6 \\
& $k_{c a t}\left(\mathrm{~s}^{-1}\right)$ & 52.2 & 20.4 & 11.0 \\
\hline
\end{tabular}

Table 3. Kinetic constants of oxidized and reduced AtG6PDH1, 2, and 3 determined by NADPH-linked spectrophotometric assays. Each number was determined from by a modified Michalis-Menten equation which includes substrate inhibition. Data points used in model fitting were $n=3$ different preparations. 


\begin{tabular}{ccc}
\hline & $\begin{array}{c}\text { Midpoint potential, } E_{m}(\mathrm{mv}) \\
\text { Enzyme or metabolite }\end{array}$ & \% reduced at $-378 \mathrm{mV}$ \\
\hline G6PDH & -378 & 50.0 \\
Ferredoxin & -410 & 7.0 \\
NADPH & -380 & 46.0 \\
Thioredoxin $f$ & -350 & 90.6 \\
Thioredoxin $m$ & -360 & 81.1 \\
NADP-MDH & -390 & 27.5 \\
FBPase & -375 & 56.0 \\
PRK & -355 & 86.5 \\
Cyclic electron flow & -330 & 98.0 \\
\hline
\end{tabular}

Table 4. Midpoint potentials and percent reduction of key Calvin-Benson cycle enzymes and electron transport proteins at $\mathbf{- 3 7 8} \mathrm{mV}$ at $\mathbf{p H ~} 8$, assuming equilibrium. Calvin-Benson cycle enzymes are mostly active at the midpoint potential of G6PDH. One electron chemistry is assumed for ferredoxin and two electron chemistry for all others. 


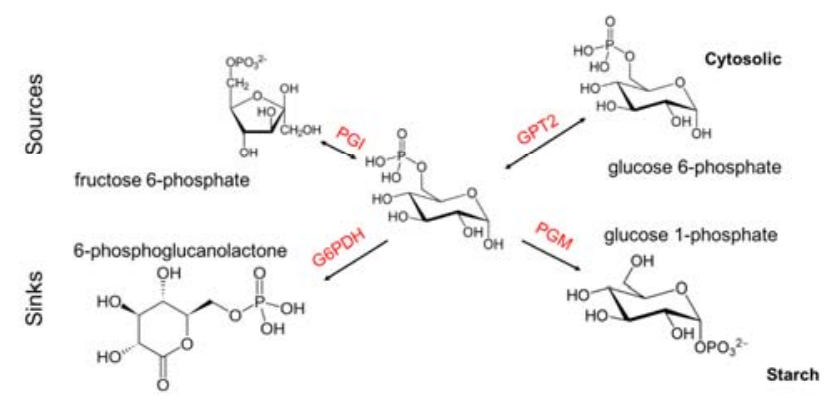

Fig 1. Production and consumption of plastidic G6P. Plastidic G6P can be produced by PGI isomerization of F6P, transported across the plastidic membrane by GPT2, consumed by PGM for starch synthesis, or consumed by G6PDH to enter the G6P shunt.

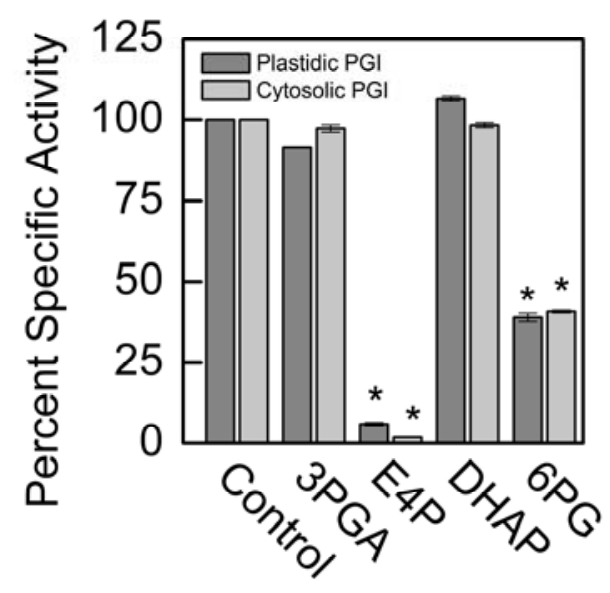

Metabolites

Fig 2. Comparison of specific activity of plastidic (a and b) and cytosolic (c and d) AtPGI with various metabolites Each bar represents mean and error bars represent S.E. (n=3). All metabolites were screened at 1:1 F6P substrate to metabolite. Data with an asterisk (*) are significantly different from the control as determined by Student's t-test $(\mathrm{P}<0.05)$. 

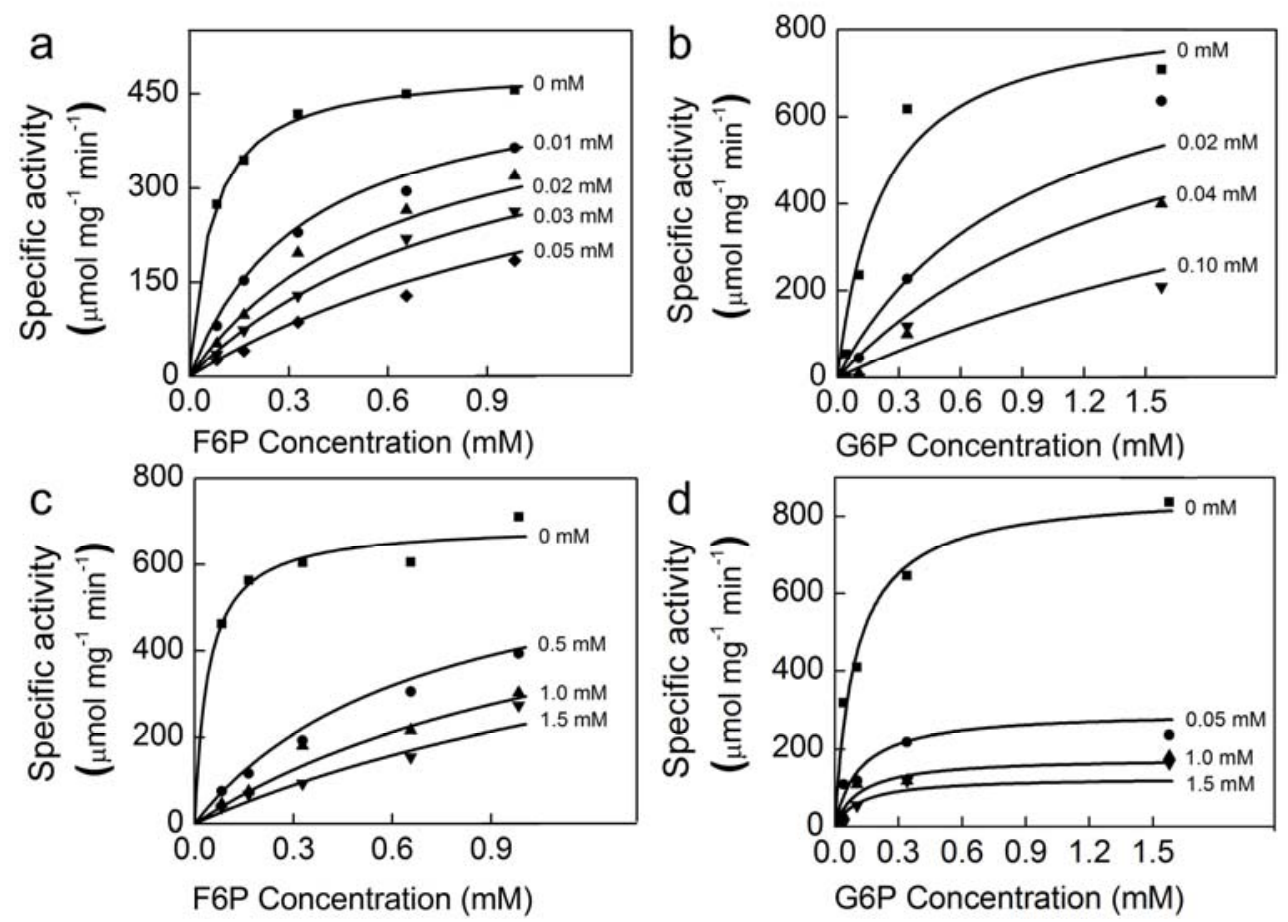

Fig 3. Effect of E4P (a, b) and 6PG (c, d) on plastidic AtPGI. Different symbols represent different concentrations of inhibitor. PGI was more inhibited by E4P than by 6PG. Lines represent data fit to Eq. 3.

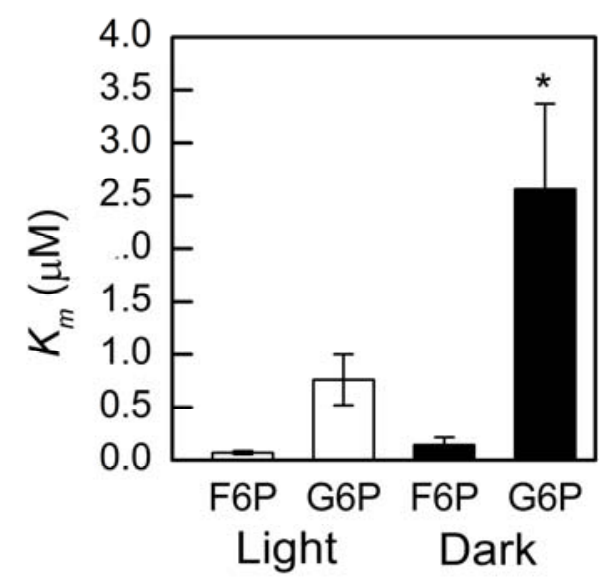

Fig 4. Comparison of G6P and F6P $K_{m}$ in plastidic SoPGI in dark and light-treated isolated spinach chloroplasts. Each bar represents mean and error bars represent S.E. $(n=3)$. The $K_{m}$ for G6P increased in dark treated compared to light treated isolated chloroplasts. Bars with a cross (+) are significantly different from corresponding light treated samples as determined by Student's t-test $(\mathrm{P}<0.1)$. 


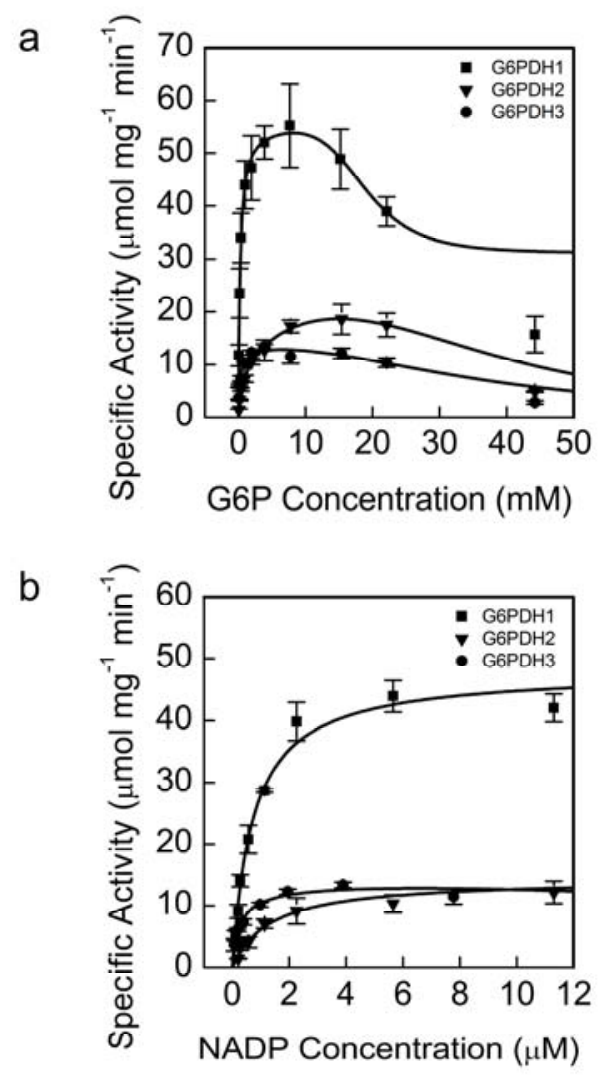

\section{Fig 5. Kinetics of AtG6PDH1, 2, and 3 at different G6P (a) and $\operatorname{NADP}^{+}(\mathrm{b})$ concentrations.}

Each data point represents mean and error bars represent S.E. $(n=3)$. All three isoforms of oxidized G6PDH showed substrate inhibition for G6P. G6PDH1 and 3 showed the greatest affinity for G6P and G6PDH3 had the greatest affinity for NADP ${ }^{+}$. During the G6P experiments $\mathrm{NADP}^{+}$was $0.6 \mathrm{mM}$ and during the $\mathrm{NADP}^{+}$experiment G6P concentration was $7 \mathrm{mM}$ for G6PDH1 and 3 and 15 mM for G6PDH2. In (a) lines represent data fit to Eq. 2 and in (b) lines represent data fit to the Michaelis-Menten equation. 


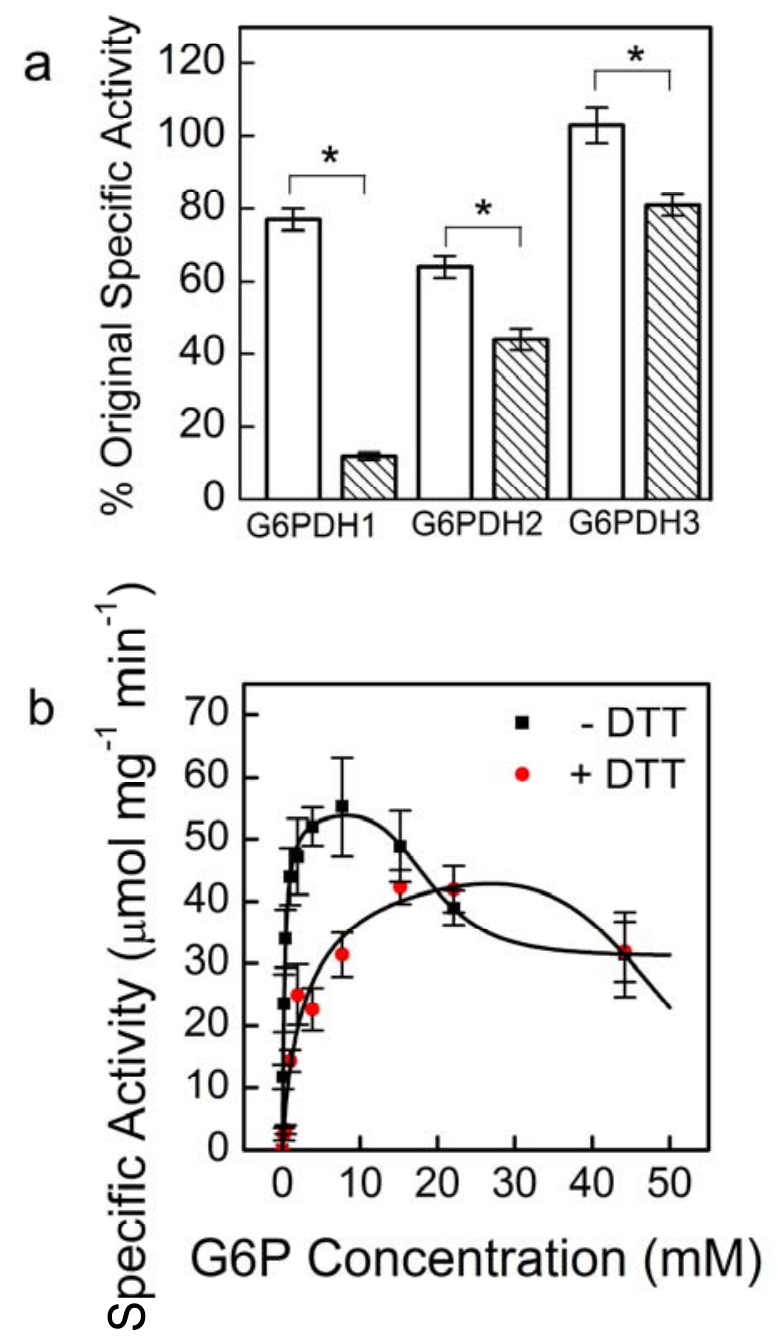

Fig 6. Activity of AtG6PDH 1, 2, and 3 with and without DTT treatment (a) and $K_{m}$ shift with DTT in G6PDH 1 (b). Each bar or data point represents mean and error bars represent S.E. $(n=3)$. G6PDH1 was the most affected by DTT treatment. White bars indicate controls incubated without DTT for 30 minutes and shaded bars represent incubation with $10 \mathrm{mM}$ DTT for 30 minutes. Assays were done with $5 \mathrm{mM}$ G6P for G6PDH1 and G6PDH3, and $15 \mathrm{mM}$ for G6PDH2. The lines represent data fit to Eq. 2. Bars with an asterisk (*) are significantly different from corresponding controls as determined by Student's t-test $(\mathrm{P}<0.05)$. 


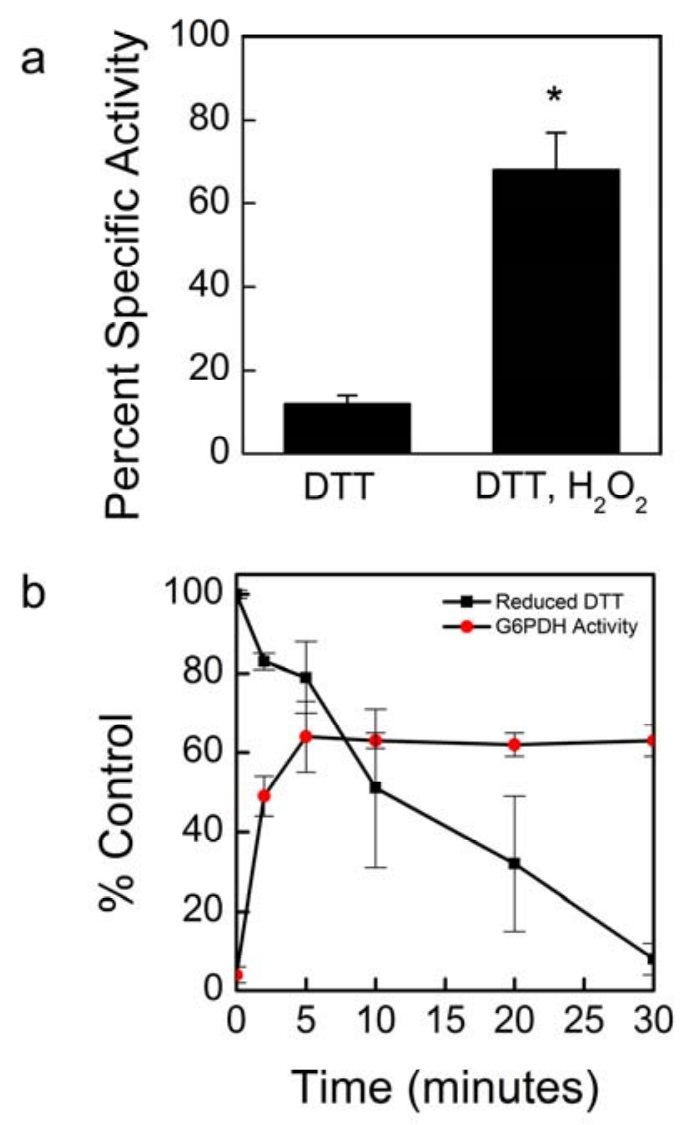

Fig 7. Activation of DTT-deactivated AtG6PDH1 with hydrogen peroxide treatment.

G6PDH1 deactivation by DTT could be recovered by addition of equimolar hydrogen peroxide.

(a). Reactivation is not through DTT oxidation, but rather hydrogen peroxide directly effects G6PDH1 (b). Assays were done with 5 mM G6P. Each bar or data point represents mean and error bars represent S.E. $(n=3)$. Bars with an asterisk $\left(^{*}\right)$ are significantly different as determined by two tailed Student's t-test $(\mathrm{P}<0.05)$. 


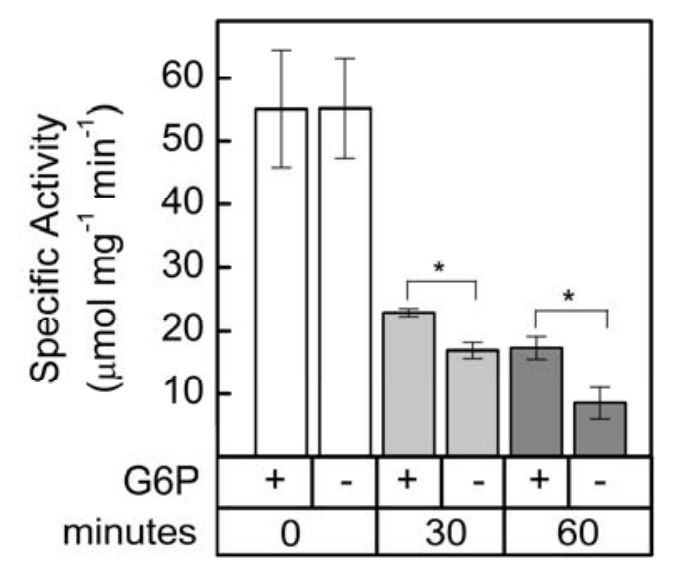

Fig 8. AtG6PDH1 protection from deactivation by G6P. G6PDH1 is less deactivated by DTT after 30 and $60 \mathrm{~min}$ when $\mathrm{G6P}$ is present at $5 \mathrm{mM}$. Each bar represents the mean and error bars represent S.E. $(n=3)$. Bars with asterisk $(*)$ are significantly different as determined by two tailed Student's t-test $(\mathrm{P}<0.05)$.

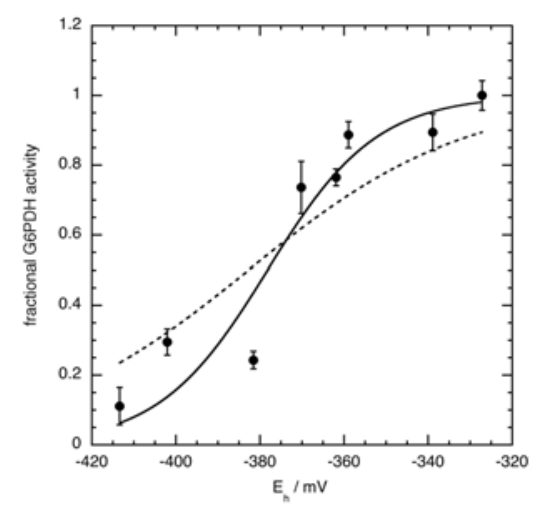

Fig 9. AtG6PDH1 midpoint potential. The midpoint potential of G6PDH1 was determined to be $-378 \mathrm{mV}$ at $\mathrm{pH}$ 8. Assays were done at the $K_{m}$ concentration of G6P for oxidized G6PDH1, $0.3 \mathrm{mM}$. Each data point represents the mean and error bars represent S.E. $(\mathrm{n}=3)$. The dashed line represents the Nernst equation for one electron. The solid line represents the Nernst equation for two electrons. 


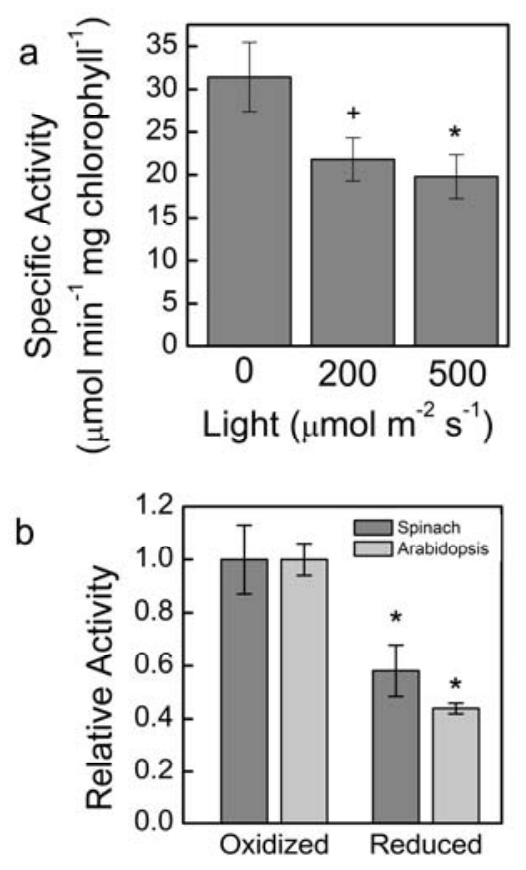

Fig 10. Whole leaf and chloroplast activity of G6PDH in Arabidopsis, and spinach. Whole leaf activity of AtG6PDH decreased 35\% after illumination (a). This represents the total redox sensitive G6PDH fraction in Arabidopsis leaves. Chloroplast G6PDH activity decreased 50\% after reduction by DTT (b). Samples were normalized by $\mu \mathrm{mol} \mathrm{min}^{-1}$ of activity per $\mathrm{mg}$ of chlorophyll added to the assay mixture. Assays were done with $5 \mathrm{mM}$ G6P. Each bar represents the mean and error bars represent S.E. $(n=3)$. Bars with a plus sign $(+)$ are significantly different as determined by two tailed Student's t-test $(\mathrm{P}<0.1)$. One asterisk $(*)$ signifies statistical difference as determined by two tailed Student's t-test $(\mathrm{P}<0.05)$ 

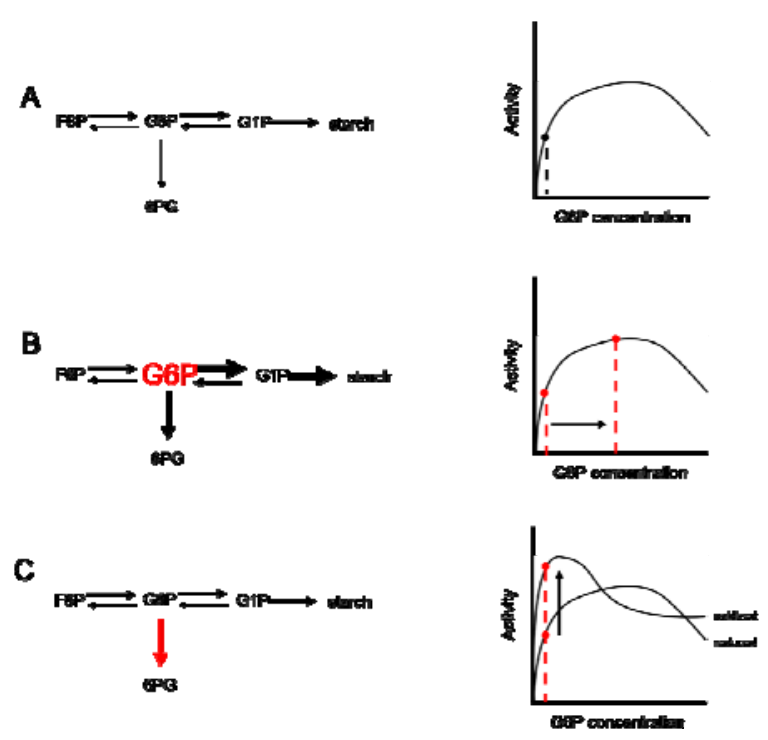

Fig 11. Model of production and consumption of glucose 6-phosphate in the chloroplast stroma through the G6P shunt. Under normal conditions, there may be flux through the G6P shunt as well as flux to starch synthesis (a). Flux through the G6P shunt can by modulated either by an increase in G6P substrate (b) or an increase in G6PDH activity (c). Arrows represent activity of enzymes and changes in thickness represent relative changes in flux. Red represents changes in the steady-state conditions. 


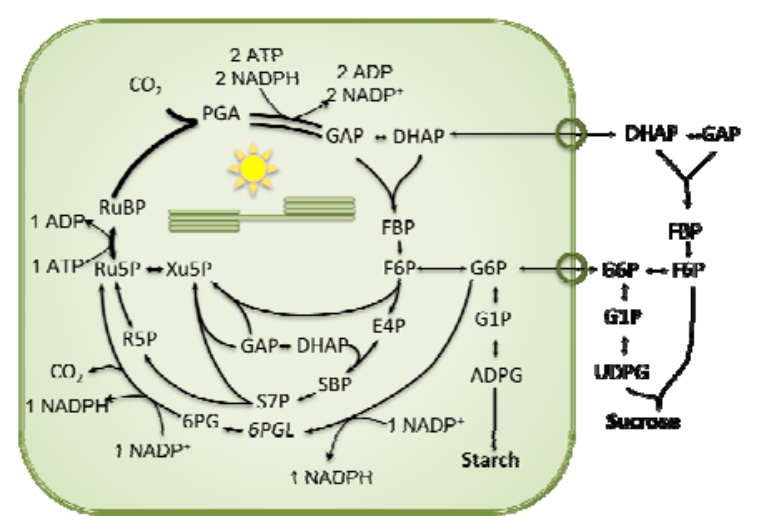

Fig 12. The glucose 6-phosphate shunt. G6PDH is consumed by G6PDH to enter the G6PDH shunt. G6P re-enters the Calvin-Benson cycle as Ru5P. Overall, the shunt consumes three ATP and two NADP ${ }^{+}$and produces two NAPDH. One $\mathrm{CO}_{2}$ molecule is lost for every G6P that enters the shunt. 